\title{
Public Consultation: Adding Value or Impeding Policy?
}

\section{Bill Kerley and Graeme Starr}

7 here is a growing expectation among interest groups of all kinds that they will be consulted at relevant stages of public policy development. It is now

an accepted fact of Australian political life that organisations will consult their stakeholders at crucial stages in their key decision-making processes. There has also been a trend towards the institutionalisation of such arrangements.

This trend has not been peculiar to Australia. When governments consider new forms of regulation, delegated legislation or public rule making, sophisticated consultative arrangements have become a dominant feature of the process. In this respect Australia has followed overseas trends. The Organisation for Economic Cooperation and Development (OECD) has noted that 'a strong trend towards renewal and expansion of public consultation in regulatory development' (OECD, 1995 ) is under way in its member countries. The OECD has expressed strong approval of this trend and has championed it with the adoption and wide publication of a set of six propositions extolling the benefits of public consultation:

- Proposition 1 ('Quality Regulations') - through the provision of a wider range of information, public consultation can encourage the development of better quality legislation and regulations;

- Proposition 2 ('Increased Options') - public consultation can contribute to the identification of more acceptable and viable policy options;

- Proposition 3 ('Lower Costs') - public consultation can lower costs to business and administration;

- Proposition 4 ('Concurrence and Compliance') - public consultation can promote concurrence and compliance with the resulting laws and regulations;

- Proposition 5 ('Responsiveness to Change') - with a public consultation strategy in place, government agencies are better placed to respond to changing circumstances and to review laws and regulations accordingly; and

- Proposition 6 ('Credibility and Legitimacy') - public consultation can improve the credibility and legitimacy of governmental action, win the support of the groups involved in the decision process and increase acceptance by those affected.

Bill Kerley is a Canberra based researcher and Graeme Starr is Assistant Dean, International Faculty at the Central Coast, University of Newcastle, Australia. 
The first step in evaluating consultative processes is to analyse how they have become so widespread. First, communications technology has made consultation both more feasible and potentially more effective. Secondly, in both the public and private sectors, the trend towards more sophisticated strategic management based on careful analysis of stakeholder interests and the general external environment has promoted an increasing inclination and better capacity among most organisations to consult their publics. Some areas of business and industry have exploited the opportunities inherent in the expansion of the available opportunities for policy consultation with government agencies. Business interests, especially small business organisations, have been active participants in the growing demand to be consulted by government, and this has tended to lead to new lobbying structures and strategies, driven by the attempted manipulation of consultative arrangements to achieve desirable policy outcomes.

Small business groups were especially active in seeking to manipulate government sponsored consultative processes in the 1980 s and early 1990s. Their influential lobby groups, including the Small Business Coalition and the Australian Chamber of Commerce and Industry, dominated high level discussions on policy developments affecting the small business sector. They were experts in the well-timed media release, which usually called for more consultation and regard for the 'little person'. Their high media profile helped to enmesh governments and policy makers in lengthy debate. This produced the political momentum for the creation of additional structures for consultation to reduce the political pressure on government and officials.

This produced a more sophisticated political bargaining process but not always better policy outcomes. There was little interest from small business groups in the promotion of such policies as reduced subsidies to inefficient producers, which many economists see as being more beneficial to those that the groups purport to represent (Revesz and Lattimore, 1997). Instead, export incentives and other government subsidy schemes were actively supported at the same time that competition policy reform was downplayed. Not surprisingly, even with the new consultative structures in place, such approaches by active and visible lobby groups did little to maintain their influence among frustrated government officials and policy makers.

Broader changes in the Australian political environment have also expanded the scope of group consultation. Electoral reforms, for example, enabled Independents and minor parties more easily to win sufficient representation in the Senate and the upper houses of some State Parliaments to force governments to consult much more widely on the details of their legislative programs. One effect of this was the growing role of parliamentary committees, which previously carried out little more than housekeeping tasks, but which - through their powers to control the timetable for the passage of legislation, conduct hearings and invite submissions - have developed key consultative and policy formulation functions.

The decline of the effectiveness of the traditional policy conduits - the political parties and the established business associations and related interest groups - has also redefined the processes of policy consultation. The parties can 
no longer effectively carry out their roles as conduits between the government and the governed, or as instruments for interest aggregation. Thus, those seeking to influence policy outcomes have had to look elsewhere for agencies of brokerage, information, and communication. The escalation over the past decade in the numbers of individuals and organisations whose activities can be described broadly as 'lobbying' was one of the more visible signs of the changing Canberra policy-making environment.

With such developments as the centralisation of government departments and the major interest group headquarters in the national capital and the more cluttered but increasingly accessible nature of the policy agenda, Canberra has come to resemble Washington as a focus for the lobbying industry. Also like Washington, however, as one observer described it, there are more lobbyists, but they have 'less clout' (Salisbury, 1990). Both the former Labor Government (Gruen and Grattan, 1993:62) and the Coalition Government have displayed an inclination to bypass the lobbies and seek the input of individual companies and their executives in their policy consultations. New waves of managers are emerging, attuned to these realities by experience and training, and more firms are adopting strategic issues management approaches, prefaced by the need to develop open and direct channels of communication with the government, thus contributing to the climate of consultation. This has been reflected in the increasing status of public affairs management as a new profession and of public affairs managers within most corporate hierarchies.

Along with these developments govemments have sought actively to secure stakeholder input into their decision-making processes through direct invitation and public advertisements. All levels of government in Australia have emphasised their recognition of a need to improve service delivery, to treat citizens as customers, and to devolve authority and decision-making. The trend towards a managerial outlook in the public service has meant that government departments and other executive bodies have had to be more transparent in their decisions and more sensitive to their stakeholders and other environmental forces in the development and maintenance of their management strategies. Their annual reports and specific policy documents now customarily include detailed descriptions of the structures and procedures for public consultation, although they rarely contain useful indicators of the effectiveness of the consultative processes.

Some of the regulation review processes created by state governments have been highly innovative and deserve more detailed scrutiny and evaluation. The Victorian State Office of the Regulator-General, for example, was established in 1994 to regulate and promote competition in those industries where government business enterprises have been privatised or otherwise restructured. To ensure that customers benefit from this competition, the Office is advised by a Customer Consultative Committee, which draws its membership from a wide range of peak bodies representing: customers generally; rural and remote customers; recipients of community service obligations; environmental interest groups; and industry and commerce. Relevant government departments and agencies (in such areas as electricity, water, environment, Treasury, energy, and the business portfolios) 
serve with the Committee as observers. The consultation processes with major stakeholders have been progressively strengthened and communications links have been increasingly formalised as the Office has become more heavily engaged in implementing key regulatory projects (Office of the Regulator-General, 1997).

At the federal level, consultative processes have been administratively incorporated in the legislative process. A requirement to prepare a 'Regulation Impact Statement' (RIS) to be attached to any Cabinet submission involving new or amended regulations affecting business has existed for some years. Compliance with this requirement was minimal until the introduction of comprehensive competition law and policy in 1994-95 provided a new impetus for regulation. Each RIS must contain details of consultation processes undertaken and the views elicited from the main interested parties (Productivity Commission, 1999).

Many of the fields where public consultation has been most widely used are in instances where NIMBY (not in my backyard) and LULU (locally unacceptable land use) phenomena are common. These tend to relate to matters of local or State responsibility such as land zoning, utilities, highways, service provision and similar domains of policy for which public meetings and other low levels of consultation might be used as substitutes for responsible political decision making. Although this has occurred at all levels of government, including the Federal on questions like airport developments and post office closures, it has had its most dramatic impact at the State and local level.

While consultation of this nature is often little more than a public relations exercise, there have been some cases where it has had the effect of focusing government attention on the need to train officials in effective consultation techniques. The growing demand for public consultation has changed the role of many public officials in policy positions. In many cases the interest group advocates are better trained and considerably more experienced in the public consultation processes than are the public officials, and this has created a need for skills not traditionally found in public administration. Officials need to develop skills that will enable them to:

- identify relevant stakeholders and assess their legitimate demands;

- organise research techniques such as focus groups, and communications opportunities such as public meetings;

- facilitate conflict management; and

- generally manage the consultation process and its output.

The State and local governments have responded positively and many have produced useful manuals (NSW Cabinet Office, 1997) and training programs with the result that the management of public consultation has greatly improved. 


\section{Are Consultative Processes Improving Policy Outcomes?}

Although the increased use of public consultation in the policy process has met some cynicism (Lederman, 1995), there have been few rigorous attempts to evaluate these processes. In fact, increased public consultation at both the government and business levels of policy-making has been accepted largely uncritically. This may be because propositions are put forward by the supporters of particular consultative arrangements that do not encourage challenge or debate. These propositions generally support the view that public consultation creates a climate for the exchange of ideas, views and information, and thus improves public policy and the relationships among the diverse players in the policy process. This view should not always be accepted without scrutiny by policy makers.

Communities and interest groups directly affected by a proposed policy have a commonly recognised right to obtain relevant information and to express their views. However, it is an extremely difficult task to identify all those affected by major government policy proposals. In practice, it is only organised interests that can be readily identified and contacted, and can readily respond to complex policy proposals. As a result many consultations on social equity and regional impact issues have been inconclusive and have led to the parties retreating to fixed rentseeking positions, claiming that the other participants in the process had been unreasonable.

Many major consultation exercises have been dominated by arguments over compensation, especially where structural reform is at issue. Kasper, amongst other economists, has observed that this is likely to result in governments attaching higher weights to the (organised) interests of the losers than to the (often unorganised) interests of the winners from reform proposals (Kasper, 1999). Under such circumstances, governments can lose the will to introduce high growth policies and reform. Kasper suggests that the equity impacts of new policy proposals are probably unknowable in advance and unprovable (Kasper, 1999:146). Extended consultative processes on tariff reform and industry policy in recent years (especially in the automobile and textile sectors) appear to demonstrate how difficult it is to gain any general acceptance of the likely outcomes of reform proposals.

Such inconclusive consultative processes have only worn away the limited political capital for fundamental reform and produced even greater calls for compensation. In many cases, a detailed government information campaign together with a focused series of discussions over a limited period would have produced better policy.

Some of the more complex areas of government policy, such as environmental issues and Aboriginal Affairs, where international treaty obligations are a key element, have been subject to a process of consultation through exhaustion. Because they are based on 'top-down' consultation models, these processes are too unwieldy to do much more than provide a media platform 
or world stage for organised interest groups and activist participants, many of whom were the actual architects of these mechanisms in the first place. These processes tend to be designed to suit the professional negotiator and can be easily dominated, if not captured, by articulate and well-resourced groups and individuals whose interest in a strategy of consultation lags well behind their interest in a strategy of publicity.

Very little of the progress in Aboriginal affairs policy in Australia, moreover, has come about as a result of the exhaustive consultative processes and the creation of elaborate administrative and regulatory machinery. The more successful change processes in this and in other areas of social affairs have usually involved small communities where locally-based groups and their leaders have been able to create an agreed and widely understood approach to change. Credit for these successful change processes at the local level is too often claimed by the more media-wise representatives of nationally-based lobby groups, and the local participants often fail to win the recognition they deserve.

Similarly, in the field of industrial relations, the elaborate consultative processes established in the 1980s and early 1990s to reform industrial relations and introduce workplace change processes were of little more than cosmetic value. Any worthwhile initiatives at a workplace level were often derailed or overshadowed by higher level moribund consultative processes dominated by fulltime union and employer representatives. These structures were swept away with the introduction of the Workplace Relations Act 1996 and very few representatives of either side of politics can be found who regret their passing.

The failure of consultative processes to improve outcomes damages the political process in Australia. Because there is often a strong public relations component in these exercises, their real or perceived failure can result in cynicism and a lack of trust on the part of those affected, undermining credibility and legitimacy and doing little to promote concurrence and compliance. It might well be, moreover, that, because public consultation takes time to conduct properly, it increases rather than lowers costs. The time factor would appear to be worthy of more consideration. Time is a luxury that is not always available to the policy maker. In such circumstances, decisions might best be left to the political process, which is essentially about making decisions (and taking the consequences) on the basis of inadequate information, rather than building expectations through lengthy but inherently flawed consultative processes.

Recent Australian experiments with co-regulation relieve business of some of its concerns about bureaucratic compliance burdens, by using Parliament in a backstop position and putting pressure on relevant industries and groups to manage the processes and deal with quality and other issues. In effect, the Government is saying to business and other interest groups: 'Okay, you can write your own regulation and control the process, but the price for doing so is to take responsibility for making it effective because you can no longer blame the bureaucracy.' This greatly elevates the role of a more credible form of consultation and stakeholder involvement. 
The case for consultation of this type in policy areas that are highly technical and require sophistication and expertise is strong, especially where there is reasonable consensus on the public interest, and where relatively long time-frames can be tolerated. In these circumstances, high level consultation and co-regulation arrangements might be appropriate. As there is always a risk of policy capture in such approaches, however, there is a need for continued sensitivity to the possibility that the output might simply reflect the demands of well-financed and highly organised experts. Risks can be minimised through training programs and other measures to build a habit of consultation into the culture of regulatory agencies and to build a continuing dialogue with a wide range of interests.

There is a public expectation, driven to some extent by media and other community pressure, that governments will maintain and intensify consultative processes. There is good reason, therefore, to give more attention to subtleties in the meaning of consultation, the relevance of comparisons across systems, the development of flexible guidelines for new forms of cost-effective consultation, and to training programs in effective consultation for all participants in the policy and regulatory processes. Policy makers and their political analysts must reexamine consultative mechanisms more critically. They must ensure that they are adding value to the policy development process and that they are not simply adding impediments to the policy process without improving policy outcomes.

\section{References}

Gruen, F. and M. Grattan (1993), Managing Government: Labor's Achievements and Failures, Longman Cheshire, Melboume.

Kasper, W. (1999), 'Structural Change, Growth and Social Justice - An Essay', pp. 125152 in Productivity Commission, Structural Adjustment: Exploring the Issues, Workshop Proceedings, AusInfo, Canberra.

Lederman, G. (1995), 'Consultation and the Capture of Government', IPA Review 47(3):43-47.

NSW Cabinet Office (1997), Consulting on Reform: A Consultation Framework for Review of Anti-Competitive Legislation, NSW Government, Sydney.

OECD (1995), 'Public Consultation and Government Regulation', Public Management Forum 1(1), available at http://www.oecd.org/puma/sigmaweb/ (publications link).

Office of the Regulator General 1997, 'Stakeholder Consultation' available at http://www.reggen.vic.gov.au/elec_7.htm.

Productivity Commission (1999), Regulation and its Review 1998-99, AusInfo, Canberra

Revesz, J. and R. Lattimore (1997), Small Business Employment, Industry Commission, Canberra (Staff Research Paper). 
192 Non-Agenda

Salisbury, R. (1990), 'The Paradox of Interest Groups in Washington - More Groups, Less Clout', pp. 203-229 in A. King (ed.), The New American Political System, The American Enterprise Institute Press, Washington DC.

The authors are grateful to anonymous referees for helpful suggestions. The views expressed in this paper are those of the authors only and do not represent the views of the organisations they are employed by. 